\title{
Field Testing Plug-in Hybrid Electric Vehicles with Charge Control Technology in the Xcel Energy Territory
}

T. Markel, K. Bennion and W. Kramer National Renewable Energy Laboratory

J. Bryan and J. Giedd Xcel Energy

Technical Report NREL/TP-550-46345 August 2009 


\section{Field Testing Plug-in Hybrid Electric Vehicles with Charge Control Technology in the Xcel Energy Territory}

T. Markel, K. Bennion and W. Kramer National Renewable Energy Laboratory

J. Bryan and J. Giedd

Xcel Energy

Prepared under Task No. WR641000
Technical Report NREL/TP-550-46345

August 2009

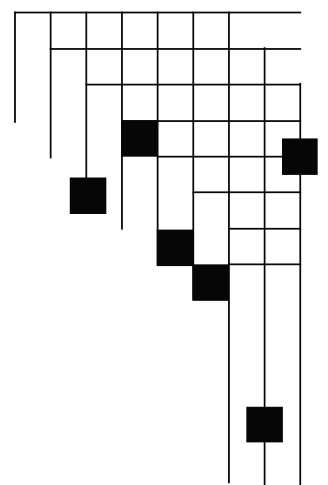




\section{NOTICE}

This report was prepared as an account of work sponsored by an agency of the United States government. Neither the United States government nor any agency thereof, nor any of their employees, makes any warranty, express or implied, or assumes any legal liability or responsibility for the accuracy, completeness, or usefulness of any information, apparatus, product, or process disclosed, or represents that its use would not infringe privately owned rights. Reference herein to any specific commercial product, process, or service by trade name, trademark, manufacturer, or otherwise does not necessarily constitute or imply its endorsement, recommendation, or favoring by the United States government or any agency thereof. The views and opinions of authors expressed herein do not necessarily state or reflect those of the United States government or any agency thereof.

Available electronically at http://www.osti.gov/bridge

Available for a processing fee to U.S. Department of Energy and its contractors, in paper, from:

U.S. Department of Energy

Office of Scientific and Technical Information

P.O. Box 62

Oak Ridge, TN 37831-0062

phone: 865.576 .8401

fax: 865.576 .5728

email: mailto:reports@adonis.osti.gov

Available for sale to the public, in paper, from:

U.S. Department of Commerce

National Technical Information Service

5285 Port Royal Road

Springfield, VA 22161

phone: 800.553 .6847

fax: 703.605.6900

email: orders@ntis.fedworld.gov

online ordering: http://www.ntis.gov/ordering.htm

This publication received minimal editorial review at NREL 


\section{Abstract}

In 2007, NREL and Xcel Energy collaborated on an analysis study to better understand the fuel displacement potential, the costs, and the emissions impacts of market introduction of plug-in hybrid electric vehicles (PHEVs) into the Xcel Energy Colorado Service Territory. The study indicated the potential for petroleum displacement and highlighted the value of vehicle charge management to limit costs and emissions impacts. As an extension and demonstration of the analysis results, a real-world fleet demonstration project was initiated. The purpose of the project was to 1) quantify the real-world fuel savings benefits of PHEVs, 2) gain an understanding of potential utility loading scenarios due to the introduction of PHEVs, and 3) develop and demonstrate the equipment and tools necessary for utility controlled charging. The project team successfully evaluated the performance of three vehicles placed in consumer service with charge control functions directed by Xcel Energy. Ten different charge control scenarios were explored, several of which correlated to the previous analysis study of 2007. Analysis of 16 weeks of field study data supports the conclusions drawn in the previous study. PHEV technology holds great promise for enabling petroleum reduction in transportation. Utility controlled charge management was demonstrated and potential load profiles were generated; some of which were synchronized with renewable resources and ancillary services suggesting that utility load management of PHEVs could provide both low $\mathrm{CO}_{2}$ transportation fuel pathways and grid operational flexibility for utilities.

\section{Table of Contents}

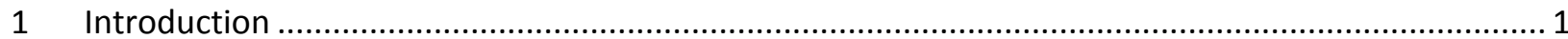

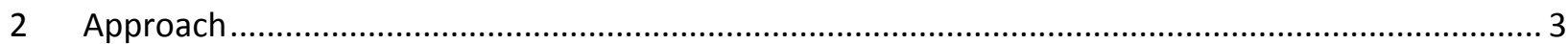

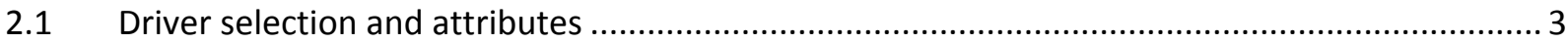

$2.2 \quad$ Vehicle selection and attributes …...................................................................................... 3

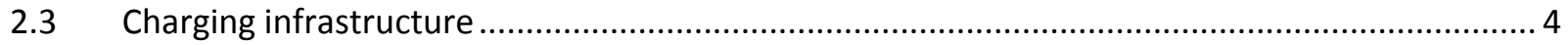

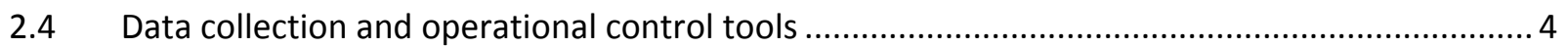

$2.5 \quad$ Operational scenarios and timeline ....................................................................................

2.6 Differences between the field test and the analysis .................................................... 6

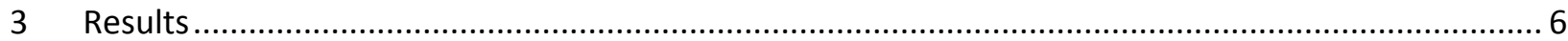

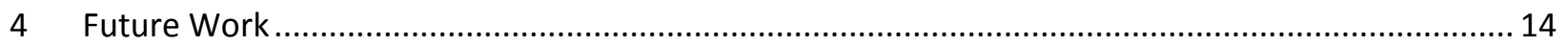

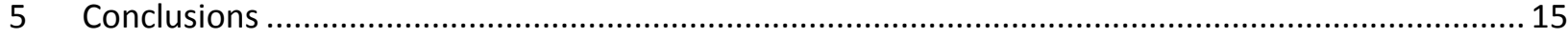

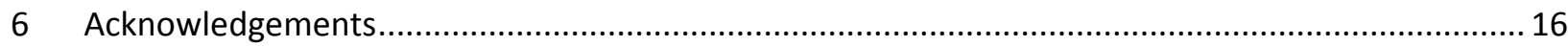

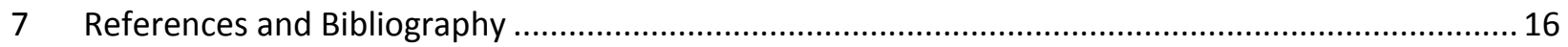




\section{Introduction}

Electrification of transportation is critical for future sustainable mobility. The world's dependence on petroleum is causing concern over future resource availability and the environmental impacts of continued fossil-fuel consumption. Plug-in hybrid electric vehicles (PHEVs), electric vehicles, and fuel cell vehicles provide opportunities for shifting transportation energy demand to the electricity network and its diverse set of resources.

PHEVs offer the opportunity to displace significant amounts of petroleum with electricity using moderately sized battery systems (relative to electric vehicles) and a reserve gasoline engine for sustained efficient operation. The costs of batteries for PHEVs remain high and alternative value streams are needed to open the door to market expansion. PHEVs can also present a challenging electrical load for the utility grid. Planning horizons for utilities require estimating load scenarios and opportunities for operational improvements many years into the future.

Hybrid Electric Vehicles (HEVs) have the potential to reduce petroleum consumption between $20-35 \%$. PHEVs can reduce petroleum consumption between $35-70 \%$ where fuel consumption is more affected by the consumer charging and driving pattern. The $\mathrm{CO}_{2}$ emissions reduction for PHEVs is less than the petroleum consumption reduction because emissions from grid power sources must be considered. The level of $\mathrm{CO}_{2}$ impact is highly dependent on the electricity source, which varies regionally. The EPRI NRDC study [1] shows the variability for PHEVs based on the source of electricity is the same as for HEVs $(\sim 30 \%)$ when from coal, $\sim 50 \%$ when from natural gas, and $66 \%$ if tied to renewables. Other studies present similar data [2-6].

In a previous collaborative study between NREL and Xcel Energy, travel survey simulation results were used to estimate several future PHEV load scenarios and their potential impact on the Xcel Energy Colorado service territory [7]. The vehicle simulations represented 227 unique driving profiles covering 24 hours of operation assuming all vehicles were PHEVs with 20 miles of urban electric driving capability. The simulation results lead to the generation of several recharge scenarios that were used to understand the costs and emissions impacts of meeting the associated new loads at several market penetration levels introduced into the Xcel Energy Colorado service territory.

The four operating scenarios considered in the simulation study were: 1) No utility control, 2) delayed charging, 3) valley fill charge, and 4) opportunity charging. The resulting load profiles expressed as kW/100 vehicles as a function of time of day are shown in Figure 1. The first three cases include a single recharge after driving is complete for the day and the fourth scenario allows recharging between trips throughout the day. These scenarios lead to petroleum consumption reductions relative to a comparable hybrid electric vehicle (HEV) of $25 \%$ for single daily charge and $43 \%$ for multiple daily charge scenarios. The impacts on the utility system were significantly different depending on the scenarios. The study assumed 500,000 vehicles or $\sim 30 \%$ of the fleet were PHEVs and highlighted that the timing of charging has important impacts on the utility operational costs and emissions. The negative impacts of coincident loading to the utility peak were encountered during 17 hours under the opportunity charge scenario and 6 hours under the no utility control scenario, suggesting that only a small amount of utility involvement would be necessary to avoid capacity expansion while offering consumers great flexibility throughout the year. The emissions impact assessment highlighted the shift in the ratio of energy resources 
serving PHEVs, which for Xcel is mainly coal and natural gas. Regardless of the source or charge scenario, the data suggest a net $15-20 \%$ reduction in $\mathrm{CO}_{2}$ emissions for PHEVs over HEVs.

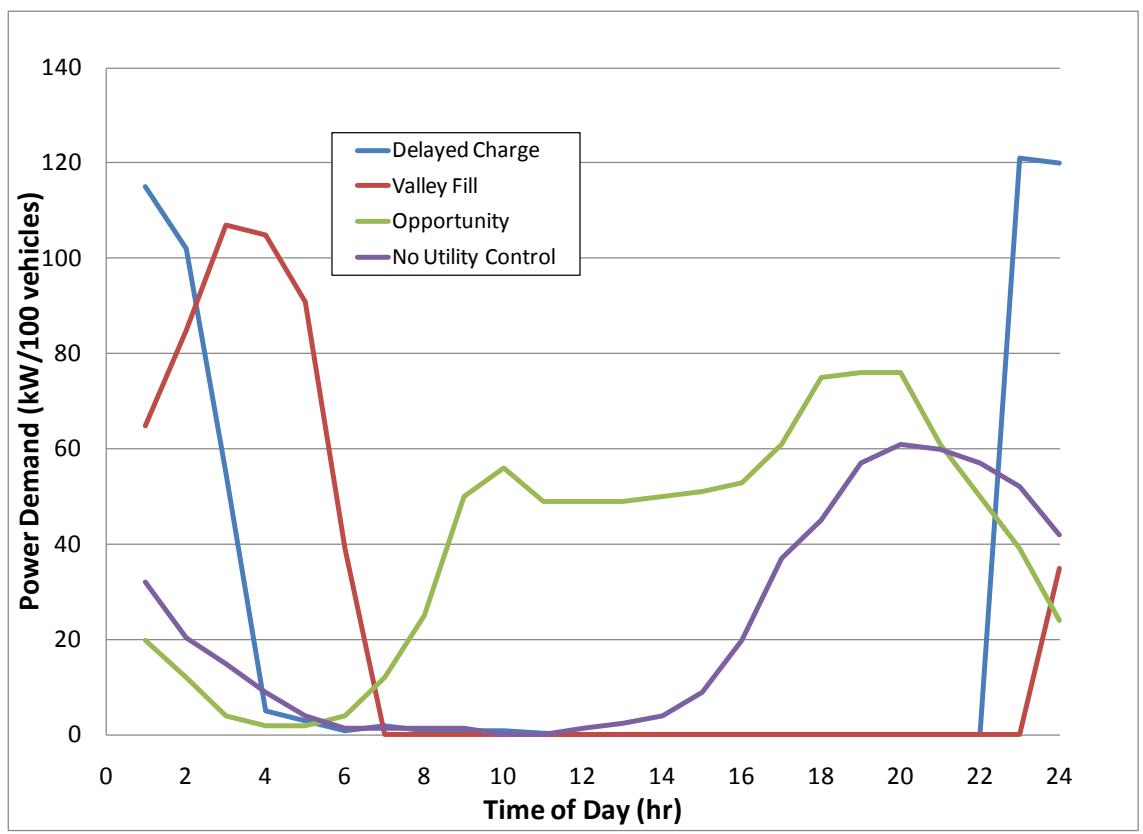

Figure 1: Generated Load Profiles for Four Charge Scenarios of a Fleet of PHEV20 Vehicles

The conclusions from the analysis study justified a real-world field test of the state of PHEV technology in the Xcel Energy service territories. The field test of PHEV technology was intended to explore the in-use experience of PHEV fuel saving benefits. Potential impacts and benefits to utility operations were also of interest. Key questions of interest included:

- Are in-use PHEV load profiles similar to the simulated ones?

- Can utilities successfully communicate with and control vehicle charging?

- Do various charge scenarios affect vehicle fuel displacement potential significantly?

- Do various charge control scenarios significantly affect the capacity of a vehicle to support ancillary services?

- Will consumers plug in their vehicles consistently?

Vehicle to grid or the ability to both charge and discharge the battery of the vehicle while tied to the utility grid was also an intended test scenario. However, technology development hurdles limited the study to consider charge control scenarios only. Vehicle to grid has been suggested to provide a valuable service to utilities that may offset the high incremental cost of PHEVs and aid in market expansion. Charge control capabilities as studied here can provide similar benefits with reduced capacity per vehicle.

Vehicle to grid also presents a new challenge in that the vehicle becomes a mobile distributed resource. As such, the interconnection standards as defined in IEEE 1547 should apply [8]. Vehicles satisfying these interconnection standards would offer utilities mobile resources with 
safety and response expectations similar to those of existing distributed energy resources.

Distributed energy resources, including both generation and energy storage, are critical elements of the evolving smart, green, clean, and efficient utility grid.

\section{Approach}

The goal of the current effort was to evaluate, under real-world conditions, the performance attributes of PHEVs with charge control technology in the Xcel Energy service territories. This was accomplished through collaboration between Xcel Energy, Hybrids Plus, V2Green, and NREL. The project required the selection of drivers, vehicles, and control hardware, data logging equipment, test scenarios, and analysis. The overarching intention was to expand our knowledge of PHEV benefits, consumer usage, and utility opportunities and challenges.

\subsection{Driver selection and attributes}

Test drivers were selected from current Xcel Energy employees who had electrical service with Xcel Energy and who completed a survey describing both their driving profile and their interest in the project. Three employees were selected whose travel behavior was similar to national average daily distances and who traveled to and from work during normal "rush" hours. Two employees were located in Denver and one was located in Minneapolis/St Paul with each driver experiencing slightly different travel conditions during their commute to and from work.

One requirement of the drivers was that both their work location and home location be located within the $3 \mathrm{G}$ data network. Electrical outlets were provided in both home and work locations and the drivers were encouraged to plug the PHEVs in every time they were at work or home for more than a few minutes and were not informed as to when the vehicle would be charging. The test drivers were not limited to driving the PHEVs to and from work, but rather were encouraged to drive the PHEVs as their everyday vehicle in order to replicate a real life situation.

\subsection{Vehicle selection and attributes}

Ford Escape HEVs were chosen for the study. Xcel Energy had experience with Ford Escapes in

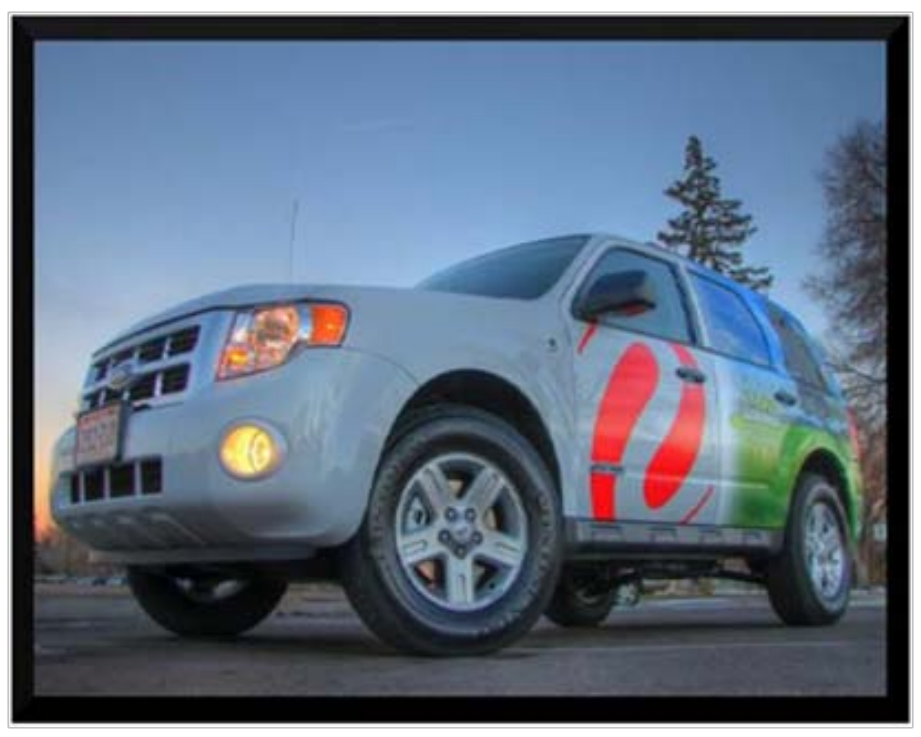

Figure 2: Image of Xcel Energy Ford Escape PHEV the corporate fleet. Both 2006 and 2008 model year vehicles were used for the study. Figure 2 is an image of one of the test vehicles. The hybrid powertrain was substantially the same for these two model years. The base hybrid electric vehicle was converted to be a plug-in hybrid electric vehicle by Hybrids Plus. The original $1.8 \mathrm{kWh}$ NiMH battery pack of the hybrid powertrain was removed and replaced with a $12 \mathrm{kWh}$ Li-ion battery pack. The plug-in hybrid conversion included a controllable battery charger and a grid connection terminal. A data logging and communications package from V2Green (now GridPoint) was also 
installed. Communications with the vehicle were established via the cellular network whenever the vehicle was driven or parked and charging. The Ford Escape hybrid powertrain coupled with the high energy battery pack allowed battery-only operation up to $29 \mathrm{MPH}$ under light loads after an engine warm-up cycle while the battery had sufficient energy. Under higher speeds and loads, the vehicle would bias toward using the stored energy but also used gasoline energy to propel the vehicle. This operation regime is a low power blended plug-in hybrid implementation and provides approximately 50 miles of charge-depleting operation between battery recharge events. In charge-sustaining mode (beyond 50 miles) the vehicle operates at $\sim 28 \mathrm{mpg}$ while in chargedepleting mode the fuel economy was expected to be $\sim 55 \mathrm{mpg}$. Charge and discharge capability at $6 \mathrm{~kW}$ with a $220 \mathrm{~V}$ AC connection was targeted, however, the vehicles for this project were limited to $1.3 \mathrm{~kW}$ using a standard $110 \mathrm{~V} 15 \mathrm{~A}$ outlet.

\subsection{Charging infrastructure}

Availability of charging infrastructure is critical for achieving the benefits of PHEVs. Vehicles are typically parked more than $90 \%$ of a day. This parked time is often at home or at work. In this study charging infrastructure was installed both at the driver's home and at their place of work. Analysis of NHTS data by Tate, et al. suggests that $90-95 \%$ of the vehicle fleet is parked in one of these two locations. [6] Given that the vehicles were able to use $110 \mathrm{~V}$ standard outlets, the participants also had the opportunity to use outlets beyond those of home and work.

\subsection{Data collection and operational control tools}

The collection of data during this project was a necessary element to support analysis and results summary. We used remote access data logging hardware provided by V2Green for this study. The data logger included a power flow meter, a CAN bus interface, GPS unit, and a communications system. Data parameters collected are listed in Table 1. Data were uploaded to a server whenever communication was established.

Table 1: Data Collection Parameters

\begin{tabular}{|ll|l|}
\hline Data during key on, (1 sample per second) & Data during key off, (1 sample per minute) \\
\hline Time & Engine speed (rpm) & Time \\
Lifetime Fuel Consumption & Battery Charge limit (kW or amps) & AC current (amps) \\
Fuel flow rate $(\mathrm{g} / \mathrm{s})$ & Battery Discharge limit (kW or amps) & AC voltage (volts) \\
Lifetime Odometer (km) & Engine coolant Temp (C) & Battery DC current (amps) \\
Vehicle speed (km/hr) & Brake pedal (\%) & Battery DC voltage (volts) \\
Battery DC current (amps) & Accel. pedal (\%) & Ambient Temp (C) \\
Battery DC voltage (volts) & & Battery min/max temps (C) \\
Ambient Temp (C) & Battery SOC (\%) \\
Battery min/max temps (C) & & Battery Energy Available Discharge (kWh) \\
Battery SOC (\%) & Battery Energy Available Charge (kWh) \\
Latitude (decimal deg) & Latitude (decimal deg) \\
Longitude (decimal deg) & Longitude (decimal deg) \\
Elevation (m) & Elevation (m) \\
Engine Temp (C) & Lifetime AC In (kWh) \\
Motor torque (Nm) & Lifetime AC Out (kWh) \\
Motor speed (rpm) & Plug Connection Engaged \\
Generator torque (Nm) & \\
Generator speed (rpm) & \\
\hline
\end{tabular}




\subsection{Operational scenarios and timeline}

We explored four operational scenarios in the systems analysis study completed in 2007 . These four scenarios were implemented as well as could be in the field environment. These four scenarios are:

- Opportunity -any time vehicle is plugged in it is allowed to charge regardless of where it is located (no charge control, similar to opportunity scenario from 2007 study)

- Single location -charging is allowed only at the designated home location (similar to no utility control)

- Single location with delayed charge (similar to delayed charge control)

○ Only allowed to charge between $10 \mathrm{pm}$ and $8 \mathrm{am}$

- Single location with charging centered on utility load low point (similar to valley fill control)

- 3:30am was assumed to be a typical lowest load point based on historical data

O Charge start time calculated to charge $1 / 2$ the total energy needed by 3:30am

- Charging stopped by $8 \mathrm{am}$.

Four additional scenarios were also introduced that would provide insights into additional value of PHEVs with charge control to be synchronized with renewables and other grid attributes.

- Solar charge (charging centered around the peak solar generation)

- Solar peak assumed to be at noon

$\circ$ Charging does not start before $8 \mathrm{am}$ and ends by $4 \mathrm{pm}$

$\circ$ Each vehicle charging starts such that $1 / 2$ of the energy needed is charged by noon

- Regulation signal (MW and Automatic Generation Control - AGC signal)

- Regulation power demand scaled to capabilities of vehicle test fleet such that less than $5 \%$ of the events fall outside of the fleet capabilities

$\circ$ The number of vehicles charging and thus the aggregate power load follows the need for regulation MW

- For AGC case, all vehicles charge when demand for AGC is low - directional control without magnitude control

- Wind farm balancing (MW and AGC signal)

- MW output of wind farm was scaled to the capabilities of the vehicle fleet such that less than $5 \%$ of the events fall outside of the fleet capabilities

- Represents a vehicle fleet fueled entirely by wind output

- AGC signal leads to directional control of vehicles without magnitude control

- All vehicles charge if AGC demand is reduced

- Real-time Price Point

- Historical real-time price data were used to determine charge control signal

- Allow vehicle charging anytime the real-time price is less than $\$ 70 / \mathrm{MWh}$

We collected 16 weeks of data using these scenarios. Several of the scenarios were repeated during the project to see changes in behavior and check consistency of results. 


\subsection{Differences between the field test and the analysis}

There are significant differences between the analysis work completed in 2007 and the field trials conducted in 2008. The following should be noted:

- Charging rate - the assumed recharge rate in the 2007 simulation study was $1.4 \mathrm{~kW}$ while the observed vehicle performance was typically just under $1 \mathrm{~kW}$. The difference impacts the speed at which a vehicle can be recharged and prepared for the next trip.

- Fleet size - the 2007 simulation study was based on 227 single day unique driving profiles and expanded to represent a $30 \%$ fleet penetration level. The field test resulted in three vehicles that were consistently used for consumer operation. Each scenario was run for at least one week and some for several weeks. As a result at least 18 unique data sets for each operating scenario were collected. The small sample size of the field test limits our ability to extend conclusions to a population.

- Infrastructure and consumer behavior - in the 2007 simulation study under opportunity charging, researchers assumed the consumers were perfect in always recharging the vehicle whenever parked and that charge infrastructure was ubiquitous while in the field study infrastructure was ensured at home and work only and consumer behavior impacted actually plugged-in time. This is likely to reduce the relative fuel savings potential observed in the field study relative to the 2007 simulation study.

- Vehicle architecture - The 2007 simulation study assumed all vehicles were mid-size car platform PHEVs with 20 miles of urban (moderate power $<\sim 55 \mathrm{mph}$ ) electric-only operation while the vehicles used in the field trials were sport utility vehicles with $\sim 50$ miles of chargedepleting range. EV-only operation in the field test vehicles was mainly below $\sim 15 \mathrm{mph}$. The field test vehicle energy capacity and vehicle performance would correlate to 25 miles of urban EV range capability if the powertrain was capable of operating in that manner. The consumption and displacement magnitudes would likely be greater for the SUV. The extended range of the converted Escape PHEV results in the opportunity charging scenario having less impact as the consumer almost always has available energy in the battery given typical commuting distances of 30 miles per day. A larger battery also suggests that recharge durations may be extended relative to the vehicles in the 2007 simulation study.

Regardless of differences between the studies, the field trials offered an opportunity to explore the state of technology, implementation options, consumer impacts, and future utility values.

\section{Results}

Six vehicles entered the field trial study. When testing began it was possible to collect data from four vehicles. Vehicle number 5 alone was used as a fleet vehicle. The analysis results focus on the characteristics of vehicles 2, 3, and 4 as they were used by employees and encountered fairly consistent usage profiles. The vehicles and their roles are summarized in Table 2.

The testing matrix for this field trial study was extensive. One key goal was to provide some comparison to the previous analysis simulation study completed in 2007 . To do so, four charge control scenarios that were similar to the previous work were implemented early in the study period. Additional scenarios of interest were added to provide further information on fuel consumption impacts and potential availability of vehicles to provide utility ancillary service 
functions. Ten different operating scenarios were tested over a 16-week period as described in Table 3.

Table 2: Xcel Energy PHEV Field Trials Vehicle Locations and Roles

\begin{tabular}{|l|l|l|}
\hline $\begin{array}{l}\text { Vehicle } \\
\text { Number }\end{array}$ & Location & Description \\
\hline 1 & Denver & Development Vehicle \\
\hline 2 & Minneapolis & Consumer \\
\hline 3 & Denver & Consumer \\
\hline 4 & Denver & Consumer \\
\hline 5 & Denver & Xcel Fleet Vehicle \\
\hline 6 & Denver & Data logging issues \\
\hline
\end{tabular}

Table 3: Description of Study Charge Control Scenarios and Timelines

\begin{tabular}{|c|c|c|c|c|}
\hline $\begin{array}{l}\text { Study } \\
\text { Week }\end{array}$ & $\begin{array}{l}\text { Start } \\
\text { Date }\end{array}$ & $\begin{array}{l}\text { End } \\
\text { Date }\end{array}$ & Description & Comments \\
\hline 1 & $7 / 17$ & $7 / 23$ & Opportunity Charge & $\begin{array}{l}\text { Neglected in results - assumed to be a } \\
\text { practice period }\end{array}$ \\
\hline 2 & $7 / 24$ & $7 / 30$ & Opportunity Charge & Baseline \\
\hline 3 & $7 / 31$ & $8 / 6$ & Opportunity Charge & Baseline \\
\hline 4 & $8 / 7$ & $8 / 13$ & Single Location Charge & $\begin{array}{l}\text { Charging only at Home. } \\
\text { Similar to "No Utility Control." }\end{array}$ \\
\hline 5 & $8 / 14$ & $8 / 20$ & Single Location Delayed Charge & $\begin{array}{l}\text { Starts at } 10 p m \text { and ends by } 8 a m . \\
\text { Similar to "Delayed Charge." }\end{array}$ \\
\hline 6 & $8 / 21$ & $8 / 23$ & $\begin{array}{l}\text { Single Location Valley Fill (short } \\
\text { week) }\end{array}$ & $\begin{array}{l}\text { Load centered at 3:30am. } \\
\text { Similar to "Valley Fill" } \\
\text { Short week due to demos. }\end{array}$ \\
\hline 7 & $8 / 28$ & $9 / 3$ & Testing Postponed & Demo at National Convention \\
\hline 8 & $9 / 4$ & $9 / 10$ & Testing Postponed & Demo at National Convention \\
\hline 9 & $9 / 11$ & $9 / 17$ & Single Location Valley Fill & Repeat of week 6 \\
\hline 10 & $9 / 18$ & $9 / 24$ & Charge Centered on Solar Peak & $\begin{array}{l}\text { Charging centered at noon with no } \\
\text { charge before } 8 \text { am or after } 4 \mathrm{pm} \text {. } \\
\text { Note: No communication with vehicles } \\
\text { for part of week, default to Opportunity }\end{array}$ \\
\hline 11 & $9 / 25$ & $10 / 1$ & Charge Synch with Wind (AGC) & $\begin{array}{l}\text { Decrease in AGC of Wind causes all } \\
\text { vehicles to charge }\end{array}$ \\
\hline 12 & $10 / 2$ & $10 / 8$ & Regulation Signal (MW) & $\begin{array}{l}\text { Number of vehicles requested to } \\
\text { charge was scaled with regulation } \\
\text { demand magnitude. }\end{array}$ \\
\hline 13 & $10 / 9$ & $10 / 15$ & Real-time Price Point & $\begin{array}{l}\text { Historical real-time price timeline } \\
\text { controlled charge status. }\end{array}$ \\
\hline 14 & $10 / 16$ & $10 / 22$ & Opportunity Charge & Baseline - repeat \\
\hline 15 & $10 / 23$ & $10 / 29$ & Regulation Signal Balance (AGC) & $\begin{array}{l}\text { Decrease in AGC of regulation causes all } \\
\text { vehicles to charge }\end{array}$ \\
\hline 16 & $10 / 30$ & $11 / 06$ & Charge Wind Balancing (MW) & $\begin{array}{l}\text { Number of vehicles requested to } \\
\text { charge was scaled with Wind output } \\
\text { magnitude. }\end{array}$ \\
\hline
\end{tabular}


The fuel consumption benefits of PHEVs were estimated in the simulation study to be $25-43 \%$ less than those of a comparable hybrid vehicle. In the field trials the comparable HEV is rated at $\sim 28 \mathrm{mpg}$ or $8.4 \mathrm{~L} / 100 \mathrm{~km}$. Figure 3 highlights the petroleum consumption (top) and electric consumption (bottom) rates of the each of the study vehicles across the testing period on a weekly basis. The fuel consumption of the vehicles in the field trial ranged between 4 and 6 $\mathrm{L} / 100 \mathrm{~km}$ resulting in a reduction of $29 \%$ to $52 \%$. Data for weeks 6-8 are not included as these were demonstration weeks and data for vehicles 1,5 , and 6 are not included as they did not provide useful data consistently throughout the project as highlighted in Table 2 . The electric consumption rates shown in the bottom section of Figure 3 were somewhat lower than expected and also highly variable on a week-to-week basis. The electricity consumption would be significantly affected by the total daily distance driven; driving farther than the charge depleting range ( $\sim 50$ miles) between charge events would dilute the electricity consumption data. The electric consumption rate could also be influenced by the number of daily cold engine starts. The PHEV implementation in the field trials starts the engine every time the vehicle is turned on to force engine and catalyst warm-up as an emissions reduction strategy. However, many short trips would then lead to a greater portion of driving on engine power rather than electric power. The electric consumption rate could also be affected by how often the drivers plugged in the vehicle to maintain the battery state of charge at a high level. In most weeks, there is a correlation between increased electrical consumption rate and decreased gasoline consumption rate resulting from the fuel displacement goals of the PHEV technology.
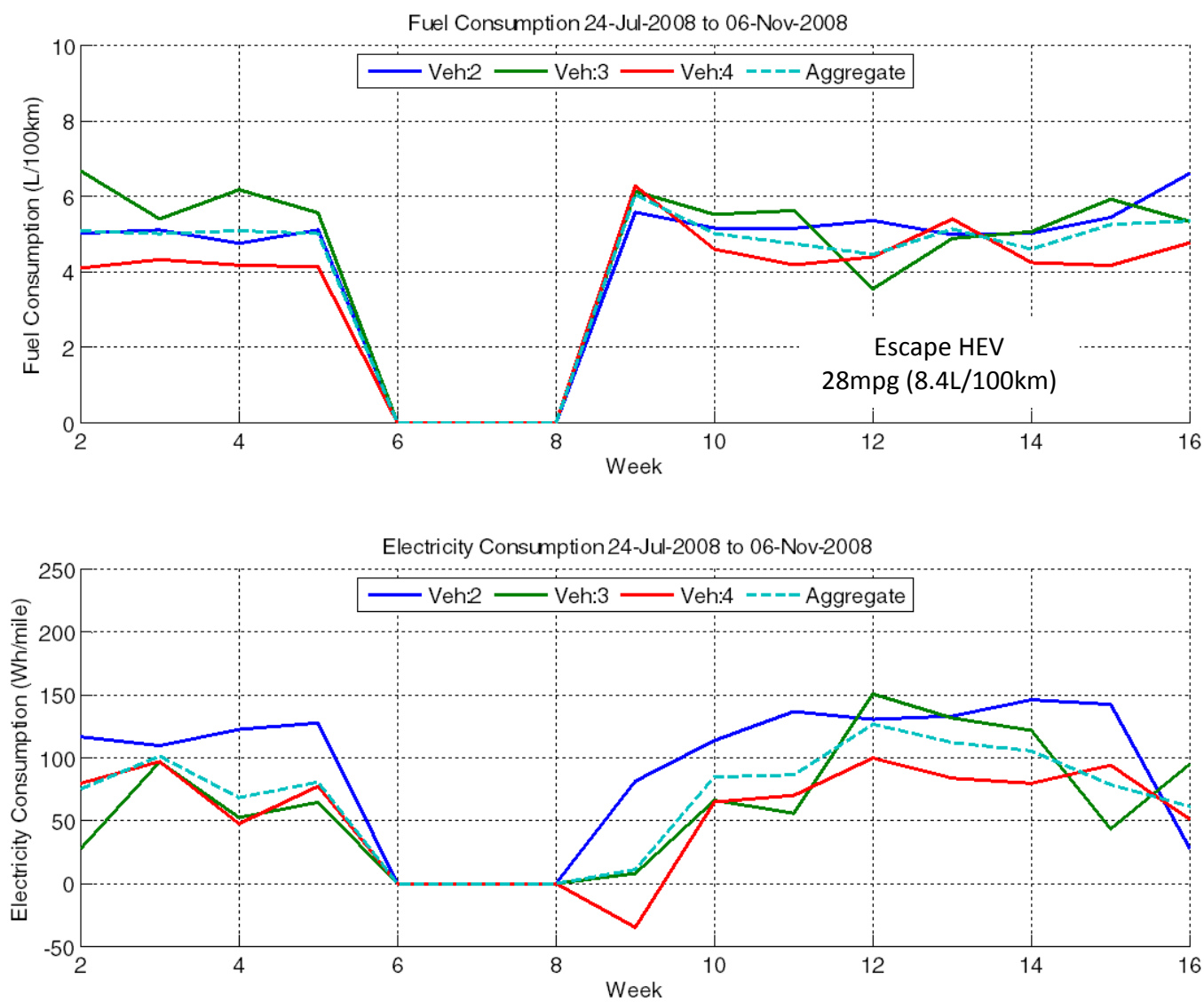

Figure 3: Weekly Petroleum and Electricity Consumption Comparison 
Figure 4 shows a summary of the fuel displacement incurred during the project for the vehicles monitored. The two weeks in the middle, with no displacement, were demonstration weeks and ignored in the analysis. Overall, more than 90 gallons of fuel were displaced. Extrapolating this to annual savings relative to the baseline HEV results in savings of about 120 gallons per year per vehicle or a savings of $\sim \$ 300$ assuming a gasoline fuel price of $\$ 2.50$ per gallon. All vehicles in this study were converted from HEV to PHEV without the support of the vehicle manufacturer. It is expected that when manufacturers create production-ready PHEV implementations that the savings could be much greater with modified engine controls and systems optimization.

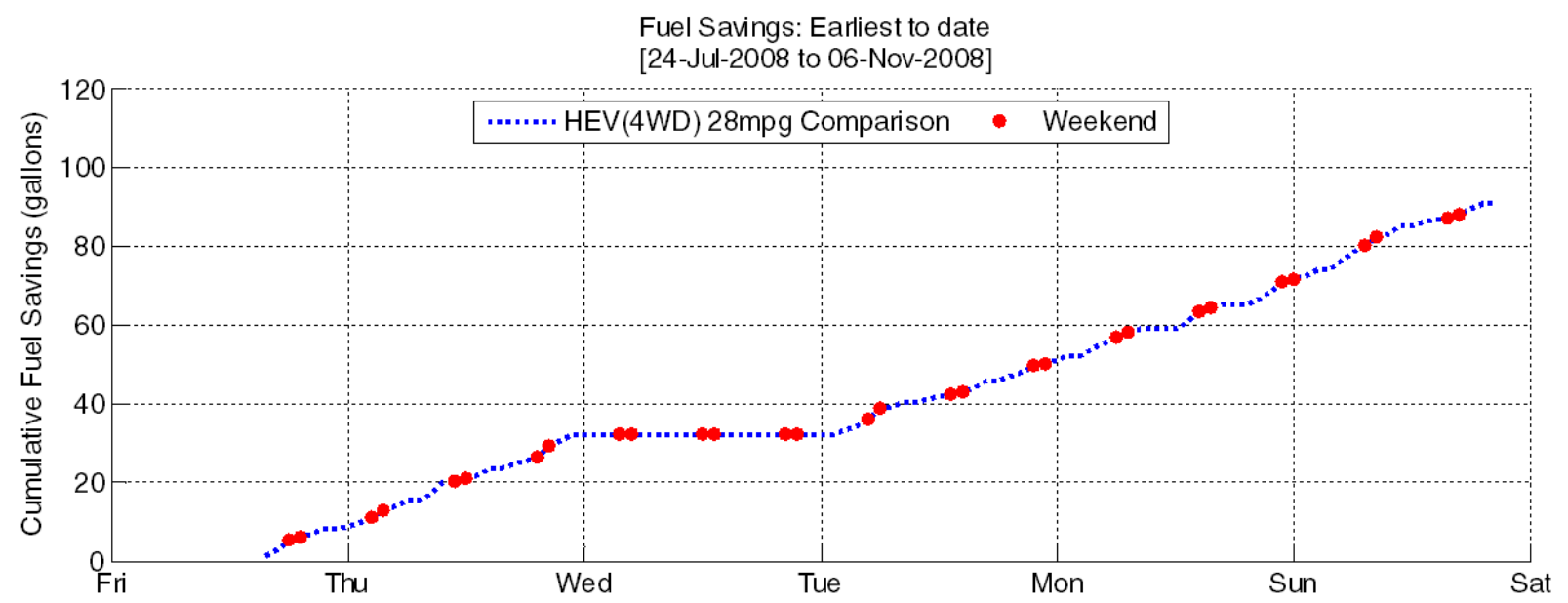

Figure 4: Project Cumulative Fuel Savings

Besides fuel consumption benefits and electricity consumption characteristics, an important purpose of this study was to understand the consumer ability and willingness to plug-in the vehicle. The more often a vehicle is plugged in, the greater the opportunity for fuel displacement. Additionally, the more often it is plugged in, the more opportunity for the utility to use the energy storage as a controllable demand-side load or even as a generation source in the future. The total time that the vehicles were parked and connected to the utility grid was measured and is reported in Figure 5. The top chart is the percentage of hours connected and the bottom chart shows the total hours. The data suggest that the behavior of the consumer changed over the duration of the project. At the beginning of the study the percentage of time plugged in was as low as $20 \%$ and a trend of increasing time plugged in is observed. The time plugged-in stabilized around $60 \%$ near the middle of the study. It is not clear what happened during weeks 13 and 16 that caused a variation in the amount of time plugged in. It should be noted that a real-time display of estimated miles per gallon was provided to the users throughout the field trial. 

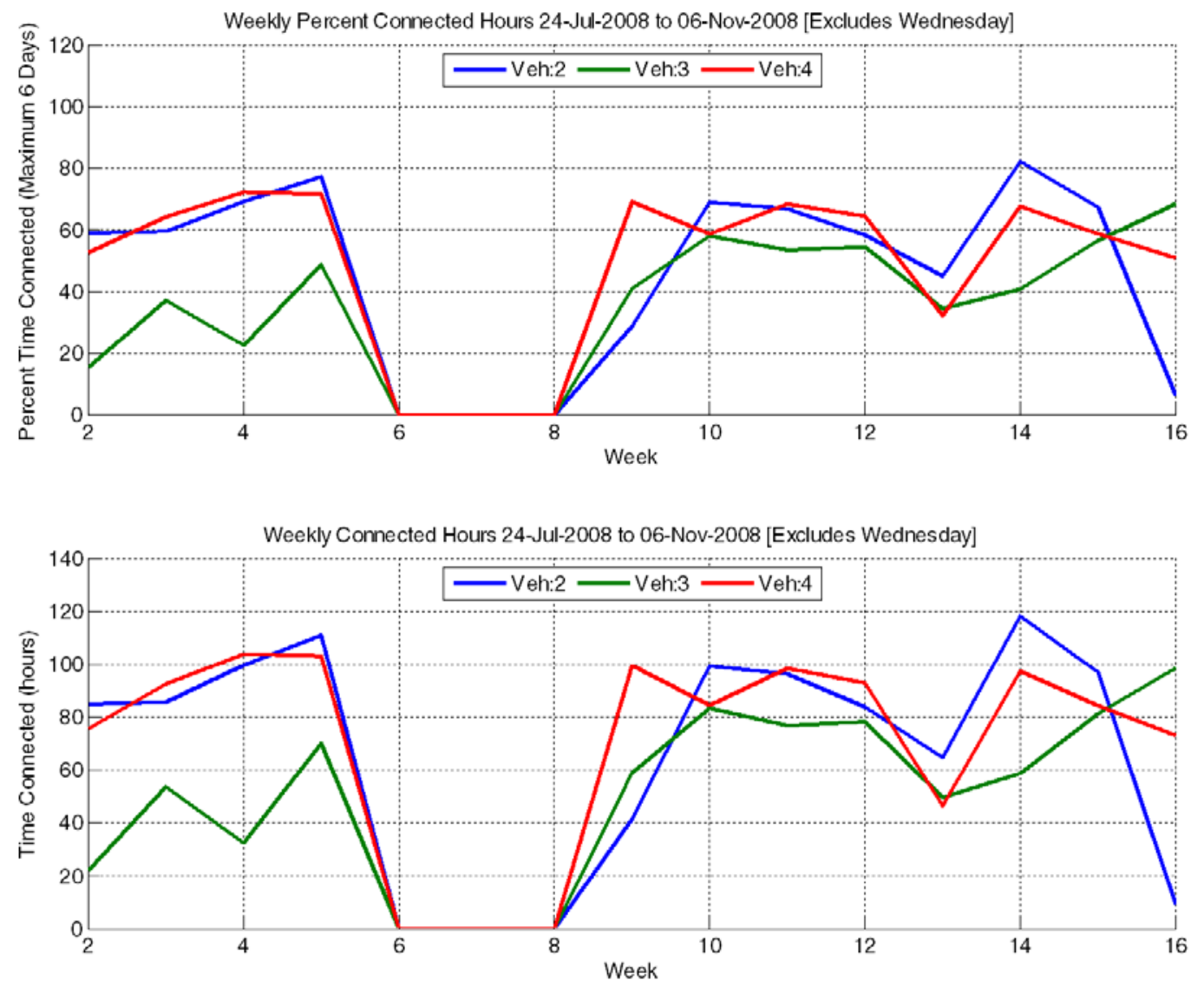

Figure 5: Percent of Time Test Vehicles are in Key-off and Connected State
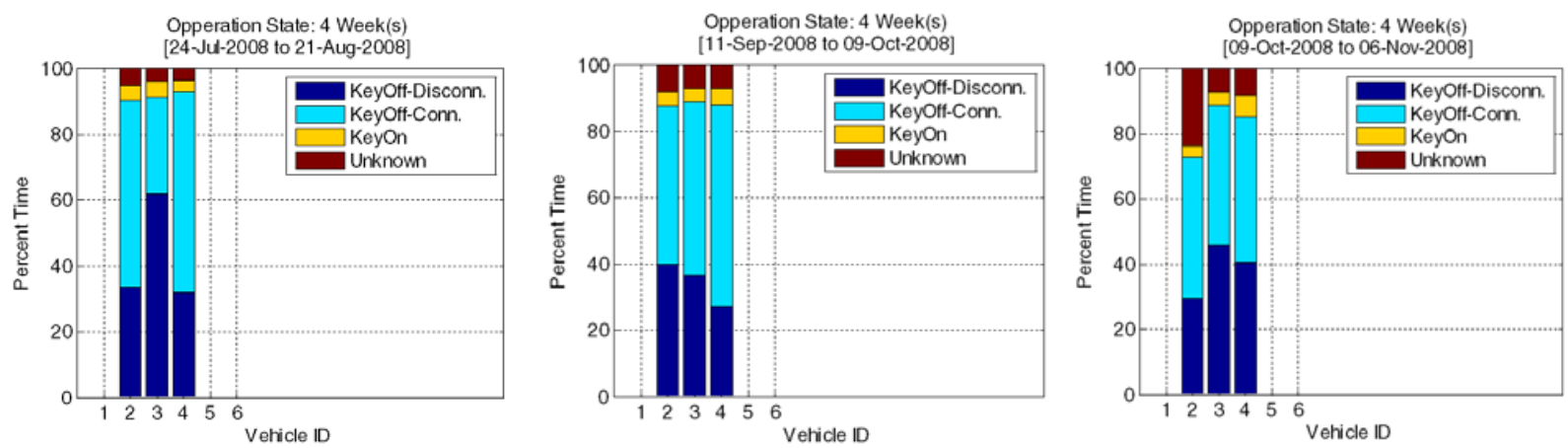

Figure 6: Operational State Comparison of Vehicles and Study Periods

Figure 6 summarizes the operational state data by vehicle for three, four-week periods during the study. Four states are identified: 1) Key On - vehicle is being driven, 2) Key Off Connected the vehicle is parked and plugged in, 3) Key Off Disconnected - the vehicle is parked but not plugged in, and 4) Unknown - the state could not be determined, maybe due to communications limitations. The Key On data support the expectation that driving constitutes a very small fraction of a vehicle's life. The connected state constitutes about $40-60 \%$ of the time and the disconnected state was $25-40 \%$ of the time. The time the vehicle was in the disconnected state could be reduced with more prevelant infrastructure and driver education or utility incentives. 
Increasing the total connected time could justify the use of vehicles as a demand side controllable load or even a reserve capacity if the vehicles were to have vehicle-to-grid power flow potential.
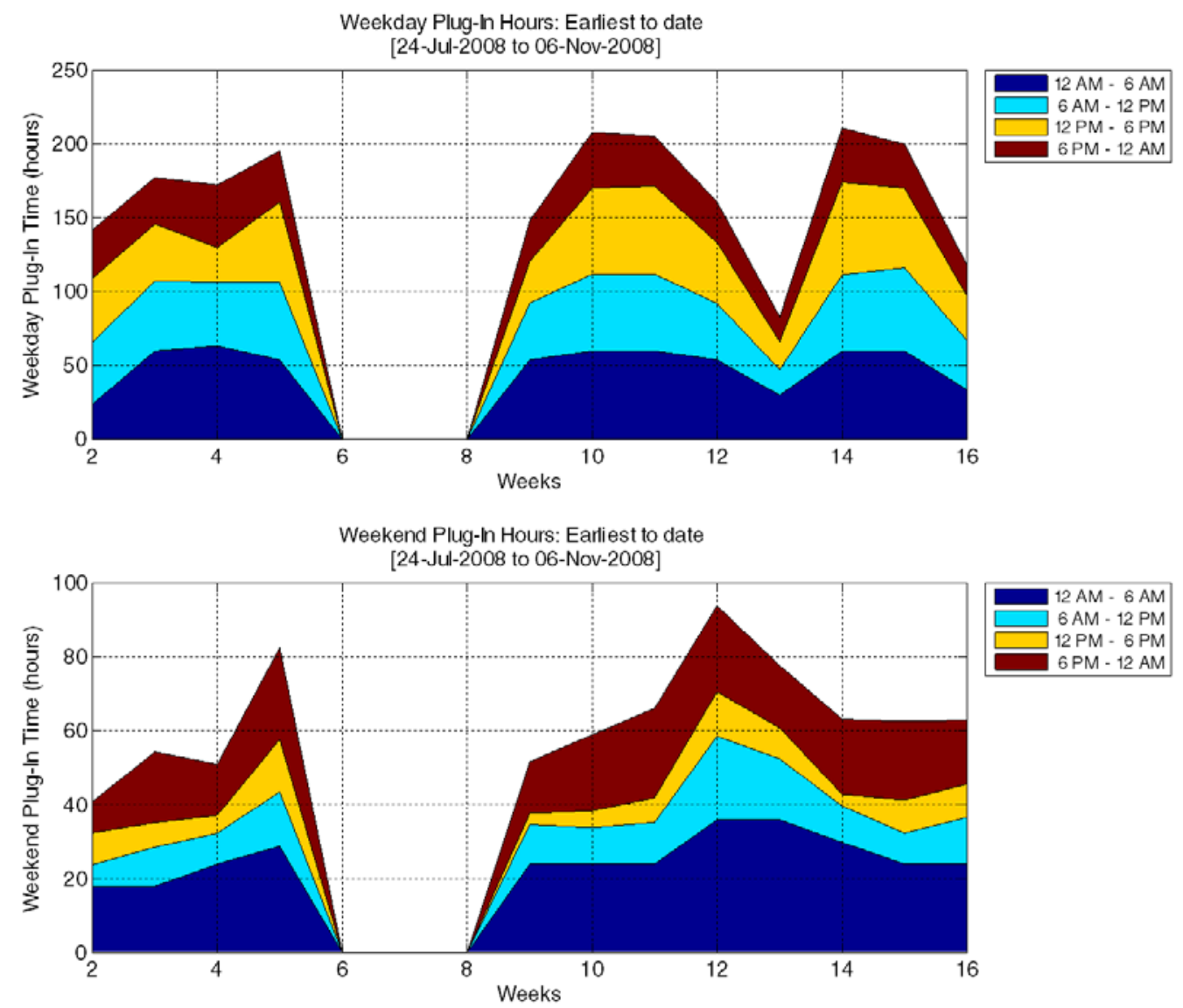

Figure 7: Plugged-in Duration by Time of Day Segment

Figure 7 slices the plugged in hours in a different way by looking at them in terms of four, sixhour time slots throughout a day. The top graph shows the results for a weekday and the bottom graph is a display of the weekend characteristics. During the weekdays, surprisingly, the time slot that seems to have the least number of plug-in hours was $6 \mathrm{pm}$ to midnight, suggesting that the vehicles may have been used more often, parked in areas without available outlets, or that the drivers chose to wait to plug in their vehicles. The weekend results were significantly different in that the mid day hours 6 am to noon and noon to $6 \mathrm{pm}$ had very limited hours of connectivity. The main difference here is most likely a result of having work place charging available during the week and limited infrastructure availability in the places where the drivers traveled on the weekends. If there was a desire for utilities to use these resources as demand-side load management programs or for ancillary services there is likely a need to explore public infrastructure opportunities such that vehicle connectivity can be ensured during all time slots and locations.

Regarding ancillary service potential, the capacity of the vehicle to provide charge or discharge power was assessed. Figure 8 provides one week of measured field data for three of the test 
weeks. The top chart is the aggregate discharge energy potential and the bottom chart is the aggregate charge energy potential. Each vehicle connected could provide approximately $10 \mathrm{kWh}$ of energy for charge or discharge depending on its current state of charge. A fully discharged battery in one vehicle when connected to the grid would represent $10 \mathrm{kWh}$ of charge potential and $0 \mathrm{kWh}$ of discharge potential. Vehicles not connected do not contribute. Charge potential represents an opportunity to increase grid load (i.e. to balance an increase in wind generation) and a discharge potential represents an opportunity to provide energy to the grid (i.e. peaking times or a decrease in wind generation). Given the charge control scenarios shown here and the fact that vehicle-to-grid was not enabled on these vehicles, they show a significant potential for discharge and limited potential for charge since the battery packs were often fully charged. Opportunity charge scenarios (not shown) showed even less opportunity for charge energy potential. The data suggest that it might be advantageous for a utility to consider V2G technologies that utilized alternative charge management strategies that provided fairly equal amounts of charge and discharge potential throughout the day (i.e. maintaining a mid-level SOC in the batteries) while still satisfying the driver's need for electrical energy to displace petroleum.
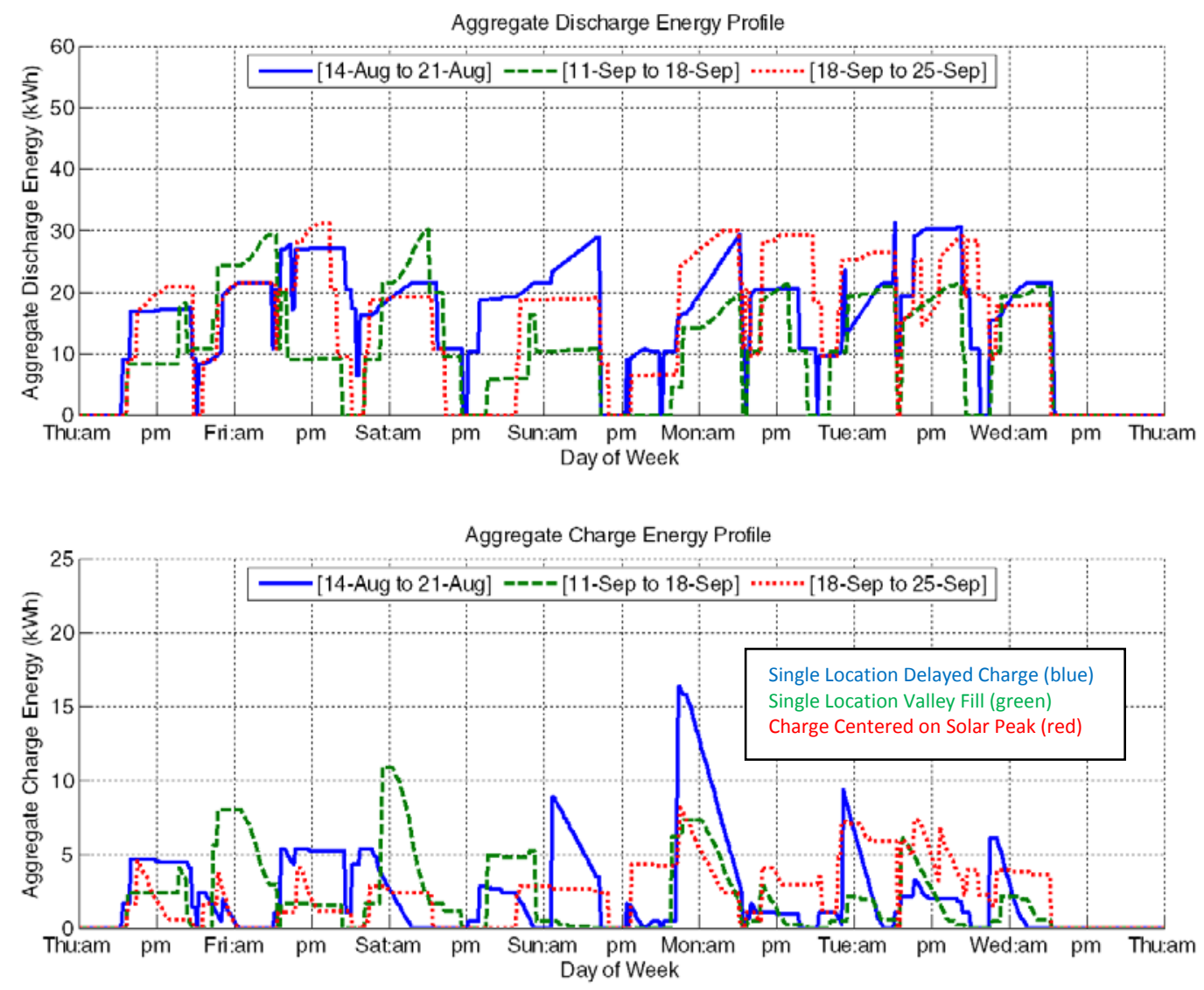

Figure 8: Charge and Discharge Aggregate Capacities of the Test Fleet during Weeks 5, 9, and 10

Finally, aggregate load profiles for several of the test scenarios were developed to compare with the load profiles derived from the 2007 simulation study. The charge management scenario can dramatically impact what the bulk loading characteristics of PHEVs will be on the utility grid. 
In Figure 9, the top chart can be directly compared to Figure 1 showing the four charge control strategies evaluated in the 2007 simulation study. In the top graph of Figure 9 the solid blue line represents Opportunity Charging and is comparable to the green line Opportunity Charge case in Figure 1. Likewise, the dashed green line in Figure 9 is Single Location Charge and corresponds to No Utility Control in Figure 1. The dotted red line in Figure 9 is Single Location Delayed and corresponds to Delayed Charge case in Figure 1. Lastly, the dash-dot light blue line in Figure 9 is Single Location Valley Fill and corresponds to the Valley Fill scenario in Figure 1. Both Figure 1 and 9 present data as $\mathrm{kW} / 100$ vehicles and the magnitudes are somewhat different. The peaks in Figure 9 are generally lower and broader. This is most likely due to the differences in the charge rate of $<1 \mathrm{~kW}$ in field test and $1.4 \mathrm{~kW}$ in the study and the battery size $\sim 10 \mathrm{kWh}$ in field test and $\sim 5-6 \mathrm{kWh}$ for the 2007 study. All four field test scenarios are surprisingly similar to those from the 2007 simulation study.
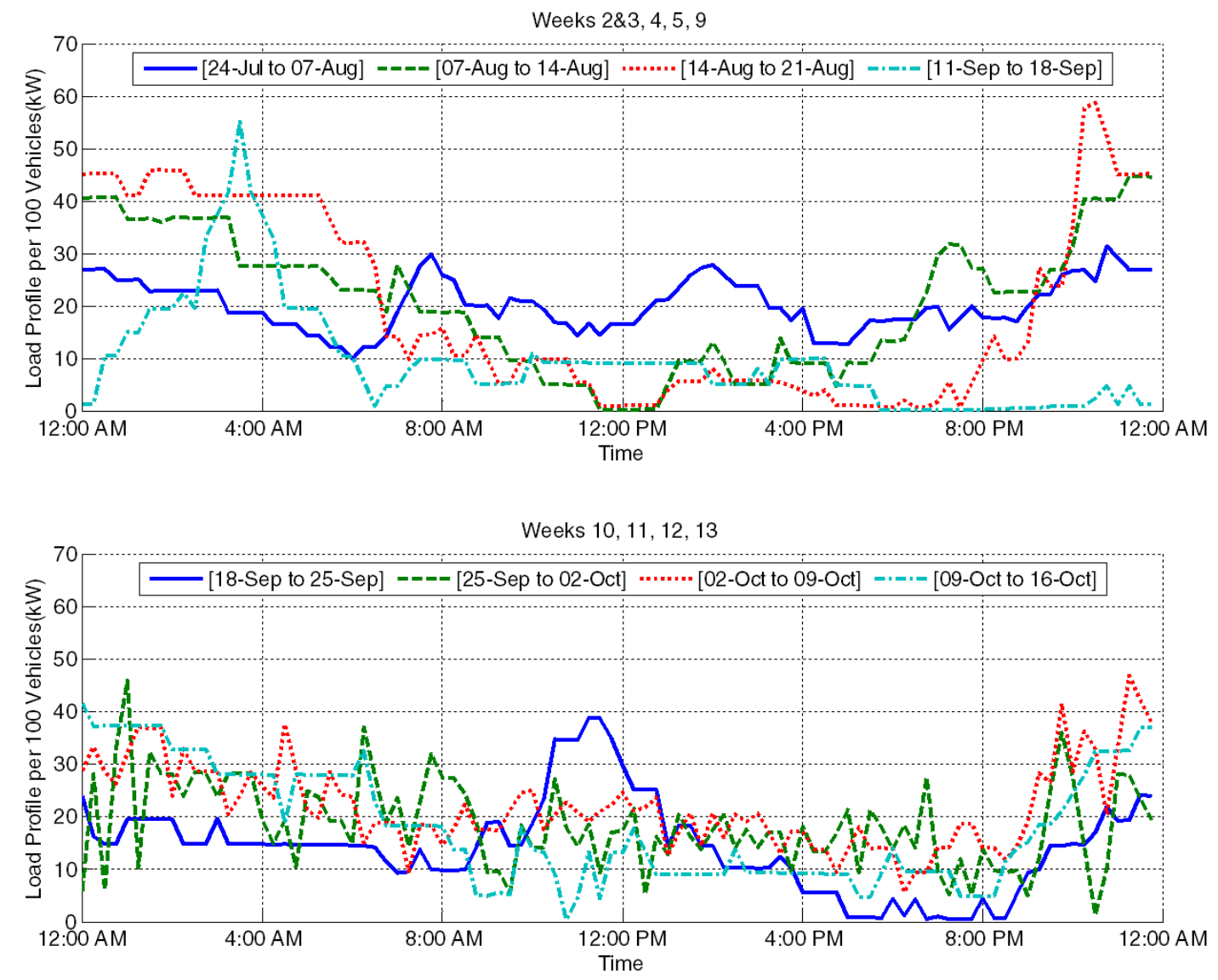

Figure 9: Aggregate Load Profile Based on Real-World Field Test Charge Scenario Data

In addition to the four scenarios from the previous study, many other scenarios linking vehicle charging to renewables, prices, and ancillary service needs were tested. The bottom half of Figure 9 describes the aggregate load of several of these additional scenarios. In the bottom graph, the solid blue line is week 10 with charging centered on the solar peak at noon, the dashed green line is charging based on a wind farm-based AGC signal, the red dotted line is the result of charging synchronized with the magnitude of the system regulation needs, and the light blue dash-dot line is charging tied to the real-time price of electricity. Both of the regulation signal 
scenarios show significant variability on short time scales but also seem to provide a moderate level load throughout the time period. The centered on solar peak has a clear mid-day peak. The scenario synched with real-time price is also valuable as it forces most of the charging to occur during evening off peak hours and resulted in a fairly smooth moderate level load.

Avoiding incremental loads coincident with the demand peak will be critical in controlling energy costs and the need for capacity expansion as the PHEV market expands. Likewise, charge management scenarios were also shown to affect the marginal emissions characteristics of the energy needed for PHEVs in the 2007 study. In the 2007 study, $\mathrm{CO}_{2}$ emissions reductions were estimated to be $15-20 \%$ relative to an HEV, independent of the charge management scenario. EPRI and NRDC published a study [1] also suggesting that for vehicles fueled solely with natural gas resources, (which is the majority of the fuel on the margin in Xcel Colorado territory) reductions of $22 \%$ would be likely. They also showed that the lowest $\mathrm{CO}_{2}$ cases were those linked with renewables showing a $48 \%$ reduction compared to a hybrid vehicle. The field study included two scenarios in which charging was directly synchronized with renewable generation. In such scenarios one would expect $\mathrm{CO}_{2}$ emissions reductions similar to those shown in the EPRI/NRDC study.

The analysis of the work conducted thus far highlights several key benefits of performing this field study. We can expect that consumer behavior and adaption throughout a study period will be significant so the duration of the study and information sharing throughout the study should be considered. It is also of great value to observe similar load characteristics in the field as those assessed in simulation studies prior to the experiment. The results suggest that electrical connectivity and electrical infrastructure requires further consideration depending on the value proposition perspective. We expect that consumers will want to purchase the smallest battery that meets their needs leading to lower purchase costs while the utility may prefer larger batteries that provide greater capacity for ancillary services. In order to provide the consumer and utilities the best value proposition, battery size and electrical infrastructure will need to be considered. An infrastructure cost benefit analysis would be beneficial. Capacity, power rating, and infrastructure availability will be important in defining the ability and benefit to utilities of shaping the PHEV load curve in the context of several operational perspectives that include cost, emissions, and distribution system congestion.

\section{Future Work}

The work conducted collaboratively between the partners in this study greatly expanded the knowledge base of all involved and will impact the research community. However, it also identified several new areas for future exploration. The following is a short elaboration of several of the most important next steps.

Market expansion of PHEVs is most likely going to occur in heterogeneous and pocketed fashion. It would be valuable to assess how the distribution system may be impacted by a role out of PHEVs of various capabilities in select communities. Specifically, Xcel Energy's Smart Grid City project in Boulder, Colorado would provide an ideal venue for measuring the distribution system impacts of PHEVs with either charge management or vehicle-to-grid capabilities. The distribution system state (e.g., congestion, thermal conditions) could be incorporated into the charge/discharge management strategy. Such a research demonstration 
should also address the challenges of control group scale. Working towards statistical group sizes of 30 or more and technology demonstration fleets of 100 or more vehicles would likely provide greater confidence in results and distribution of characteristics.

No discharge strategies could be evaluated during the test period due to limitations of the installed equipment. There is value in demonstrating the ability to support grid functions with mobile energy storage resources. Bi-directional power electronics equipment should be developed, tested, and evaluated in the field. Ideally, these units would have variable rate control to provide ability to tune the network with full range charge and discharge control of vehicle storage resources. The current field study was only capable of on/off charge control. In a related study, NREL is in the process of completing work on evaluating the impacts of plug in vehicles may have on distribution grid. [9]

For integration with smart grid endeavors it seems that a more thorough exploration of communications options is needed. Cellular/GPRS technology for data flow was used in the current testing. Other lower cost options such as power line carrier and low power wireless communication should also be evaluated as they may present more scalable options.

Finally, a more detailed study of the costs and potential value to both consumers and the utility of expanded charge infrastructure would be beneficial. The field trial showed that approximately $30 \%$ of the time the vehicles were not electrically connected to a charging plug. We expect that utilities should consider ways to provide a vehicle charging infrastructure that could allow a consistent charge/discharge management resource for future grid refined control. Further study is needed to evaluate the tradeoffs of vehicles that require high power and low power electrical interconnection.

\section{Conclusions}

Xcel Energy's leadership in technology innovation provided the opportunity to gain a better understanding of the real-world implications of a collaborative study on the benefits, the cost, and the emissions impacts of PHEVs on the Xcel Colorado Territory. A field study was conducted with a group of six vehicles of which three provided valuable data. Data were collected over a 16-week period in which 10 charge management scenarios were conducted. The primary goals of the study were to 1) quantify the real-world fuel savings benefits of PHEVs, 2) gain an understanding of potential utility loading scenarios due to the introduction of PHEVs, and 3) develop and demonstrate the equipment and tools necessary for utility-controlled charging.

The analysis summarized in this report highlights several key insights about PHEVs and charge management. The real world performance of the cars and their energy consumption characteristics even in the small fleet of this field test was sufficient to support the conclusions drawn by the analysis of the simulation study completed in 2007. Charging loads presented similar shapes as those identified earlier. Several new load shapes were also developed in the field test. In particular, load shapes tied to renewable resources, real-time price, and ancillary service needs were innovative. Fuel savings in the field correlated well with those previously estimated and were in the range of $25-50 \%$ reduction relative to the comparable hybrid vehicle. The field trial data for these three vehicles suggest little variation in fuel savings due to utility 
charge management scenarios, suggesting that such features could be acceptable to consumers. No discharge scenarios were evaluated in this specific field trial study.

Given the size of the battery and the commuting behaviors of the participants, $110 \mathrm{VAC}$ charging at home and work provided substantial benefit. For this study group, connectivity to the grid was observed $40-60 \%$ of the time. It was noted that connectivity during weekend mid-day hours was low and could likely be addressed with infrastructure expansion.

The hardware, software, and analyses conducted under this collaborative project constitutes ground-breaking work that is helping the industry accelerate its adoption of fuel saving electrified transportation technologies through integration with utility grid operations.

\section{Acknowledgements}

The authors would like to thank the Xcel Energy management team for their patience and willingness to pursue world-changing technologies. The NREL management team is also acknowledged for their support of industry partnerships and collaboration necessary to accelerate the scale and pace of energy technology adoption.

\section{References and Bibliography}

1. "Environmental Assessment of Plug-In Hybrid Electric Vehicles. Volume 1: Nationwide Greenhouse Gas Emissions.” EPRI, Palo Alto, CA: 2007. 1015325.

2. R. Sioshansi and P. Denholm. "Emissions Impacts and Benefits of Plug-In Hybrid Electric Vehicles and Vehicle-to-Grid Services.” Environ. Sci. Technol., 2009, 43 (4), pp 1199-1204, January 22, 2009.

3. A. Elgowainy, A. Burnham, M. Wang, J. Molburg, and A. Rousseau. "Well-to-Wheels Energy Use and Greenhouse Gas Emissions Analysis of Plug-in Hybrid Electric Vehicles.” Argonne National Laboratory.ANL/ESD/09-2. February, 2009.

4. S. W. Hadley, A. Tsvetkova. "Potential Impacts of Plug-in Hybrid Electric Vehicles on Regional Power Generation." Oak Ridge National Laboratories, ORNL/TM-2007/150, 2008.

5. M. Kintner-Meyer, K. Schneider, R. Pratt. "Impacts Assessment of Plug-In Hybrid Vehicles on Electric Utilities and Regional U.S. Power Grids. Part 1: Technical Analysis.” PNNL-SA-53700. 2007.

6. E. Tate and P.J. Savagian, "The $\mathrm{CO}_{2}$ Benefits of Electrification: E-REVs, PHEVs and Charging Scenarios.” SAE World Congress. April 2009. SAE Document 2009-01-1311.

7. K. Parks, P. Denholm, and T. Markel "Costs and Emissions Associated with Plug-In Hybrid Electric Vehicle Charging in the Xcel Energy Colorado Service Territory." NREL/TP-640-41410 May 2007. 
8. B. Kramer, S. Chakraborty and B. Kroposki, "A review of plug-in vehicles and vehicleto-grid capability", IEEE Industrial Electronics Society Annual Conference, IECON 2008, November 2008.

9. P. B. Evans, S. Kuloor, B. Kroposki, "Impacts of Plug-in Vehicles and Distributed Storage on Electric Power Delivery Networks." To be published IEEE Vehicle Power and Propulsion Conference. Sept. 2009. Detroit, MI.

10. J. Gonder, T. Markel, M. Thornton, A. Simpson, "Using Global Positioning System Travel Data to Assess Real-World Energy Use of Plug-In Hybrid Electric Vehicles." Transportation Research Record: Journal of the Transportation Research Board. Vol. 2017, 2007; pp. 26-32; NREL Report No. JA-540-41444. doi:10.3141/2017-04

11. P. Denholm, W. Short, "Evaluation of Utility System Impacts and Benefits of Optimally Dispatched Plug-In Hybrid Electric Vehicles (Revised)." 30 pp.; NREL Report No. TP620-40293.

12. T. Markel, A. Simpson, "Cost-Benefit Analysis of Plug-In Hybrid Electric Vehicle Technology.” (WEVA-2006-053). World Electric Vehicle Association Journal. 8 pp.; NREL Report No. JA-540-40969. 


\section{REPORT DOCUMENTATION PAGE}

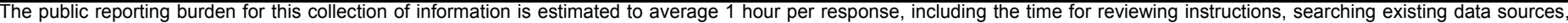

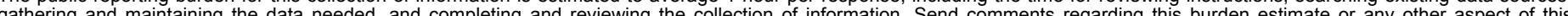

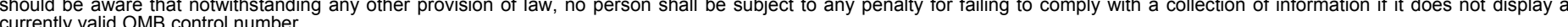

PLEASE DO NOT RETURN YOUR FORM TO THE ABOVE ORGANIZATION.

\begin{tabular}{l|l|l|l} 
1. REPORT DATE (DD-MM-YYYY) & 2. REPORT TYPE & 3. DATES COVERED (FrOm - TO)
\end{tabular}

August 2009

Technical Report

4. TITLE AND SUBTITLE

Field Testing Plug-in Hybrid Electric Vehicles with Charge Control

Technology in the Xcel Energy Territory

5a. CONTRACT NUMBER

DE-AC36-08-GO28308

5b. GRANT NUMBER

5c. PROGRAM ELEMENT NUMBER

6. AUTHOR(S)

T. Markel, K. Bennion, W. Kramer: NREL

J. Bryan, J. Giedd: Xcel Energy

5d. PROJECT NUMBER

NREL/TP-550-46345

5e. TASK NUMBER

WR641000

5f. WORK UNIT NUMBER
7. PERFORMING ORGANIZATION NAME(S) AND ADDRESS(ES)

National Renewable Energy Laboratory

1617 Cole Blvd.

Golden, CO 80401-3393

9. SPONSORING/MONITORING AGENCY NAME(S) AND ADDRESS(ES)
8. PERFORMING ORGANIZATION REPORT NUMBER

REL/TP-550-46345
10. SPONSOR/MONITOR'S ACRONYM(S) NREL

11. SPONSORING/MONITORING AGENCY REPORT NUMBER

12. DISTRIBUTION AVAILABILITY STATEMENT

National Technical Information Service

U.S. Department of Commerce

5285 Port Royal Road

Springfield, VA 22161

13. SUPPLEMENTARY NOTES

14. ABSTRACT (Maximum 200 Words)

Results of a joint study by Xcel Energy and NREL to understand the fuel displacement potential, costs, and

emissions impacts of market introduction of plug in hybrid electric vehicles.

\section{SUBJECT TERMS}

Xcel; plug-in; hybrid; PHEV; electric; vehicles

\begin{tabular}{|c|c|c|}
\hline $\begin{array}{l}\text { a. REPORT } \\
\text { Unclassified }\end{array}$ & $\begin{array}{l}\text { b. ABSTRACT } \\
\text { Unclassified }\end{array}$ & $\begin{array}{l}\text { c. THIS PAGE } \\
\text { Unclassified }\end{array}$ \\
\hline
\end{tabular}

\begin{tabular}{l|l} 
17. LIMITATION & 18. $\begin{array}{l}\text { NUMBER } \\
\text { OF ABSTRACT } \\
\text { OF PAGES }\end{array}$ \\
UL &
\end{tabular}

19a. NAME OF RESPONSIBLE PERSON

19b. TELEPHONE NUMBER (Include area code) 